\title{
Policy and programme considerations for ARV-based prevention for women: Insights from key opinion leaders in Zimbabwe about tenofovir gel
}

Samukeliso Dube

Barbara Friedland

Population Council

Saiqa Mullick

Population Council

Martha Brady

Population Council

C. Elizabeth McGrory

Follow this and additional works at: https://knowledgecommons.popcouncil.org/departments_sbsr-hiv

Part of the Demography, Population, and Ecology Commons, International Public Health Commons, and the Women's Health Commons How does access to this work benefit you? Let us know!

\section{Recommended Citation}

Dube, Samukeliso, Barbara Friedland, Saiqa Mullick, Martha Brady, and C. Elizabeth McGrory. 2014. "Policy and programme considerations for ARV-based prevention for women: Insights from key opinion leaders in Zimbabwe about tenofovir gel." New York and Johannesburg: Population Council. 



\section{POLICY AND PROGRAMME CONSIDERATIONS FOR ARV-BASED PREVENTION FOR WOMEN: INSIGHTS FROM KEY OPINION LEADERS IN ZIMBABWE ABOUT TENOFOVIR GEL}

Samukeliso Dube

Barbara Friedland

Saiqa Mullick

Martha Brady

Elizabeth McGrory 


\section{ACKNOWLEDGMENTS}

This publication was prepared by Samukeliso Dube, Barbara Friedland, Saiqa Mullick, Martha Brady, and Elizabeth McGrory. The authors would like to express their gratitude to the Zimbabwe Ministry of Health and the policymakers in Zimbabwe who willingly shared their time and expertise.

This activity was made possible by the generous support of the American people through the United States Agency for International Development (USAID). The contents are the sole responsibility of the Population Council and do not necessarily reflect the views of USAID or the United States Government.

\section{Population Council}

The Population Council confronts critical health and development issues-from stopping the spread of HIV to improving reproductive health and ensuring that young people lead full and productive lives. Through biomedical, social science, and public health research in 50 countries, we work with our partners to deliver solutions that lead to more effective policies, programmes, and technologies that improve lives around the world. Established in 1952 and headquartered in New York, the Council is a nongovernmental, nonprofit organisation governed by an international board of trustees.

Suggested citation: Samukeliso Dube, Barbara Friedland, Saiqa Mullick, Martha Brady, and Elizabeth McGrory. 2013. "Policy and programme considerations for ARV-based prevention for women: Insights from key opinion leaders in Zimbabwe about tenofovir gel." New York and Johannesburg: Population Council.

One Dag Hammarskjold Plaza

New York, New York 10017 USA

Tel: 1-212-339-0500/Fax: 1-212-755-6052

www.popcouncil.org

${ }^{\oplus} 2014$ The Population Council, Inc.

Any part of this publication may be photocopied without permission from the publisher provided that copies are distributed without charge and full source citation is included. The Population Council would appreciate receiving a copy of any materials in which the text is used. 


\section{Table of Contents}

\section{ACRONYMS}

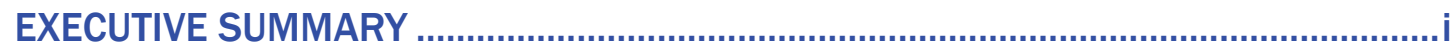

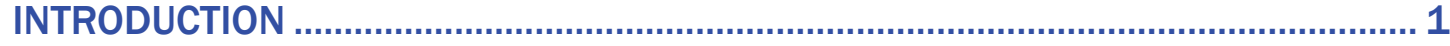

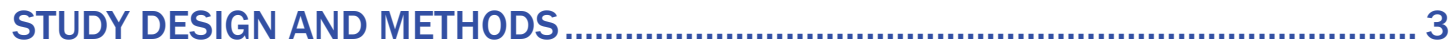

FINDINGS AND KEY INSIGHTS BY THEMATIC AREA ……....................................... 4

Scientific Evidence on Tenofovir Gel ...........................................................................

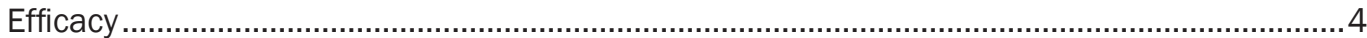

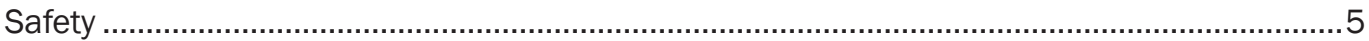

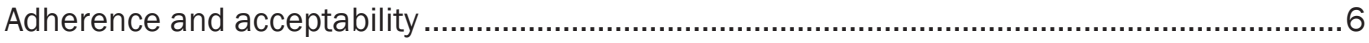

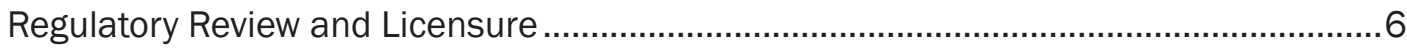

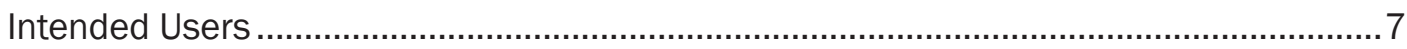

Who would benefit most from the introduction of tenofovir gel? ............................................ 7

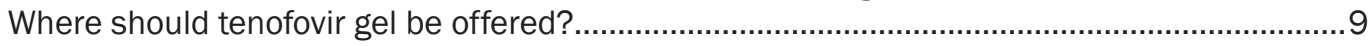

Impact on Health Systems....................................................................................... 12

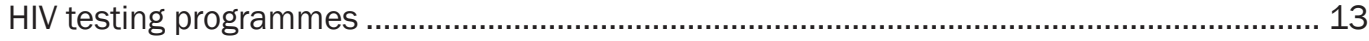

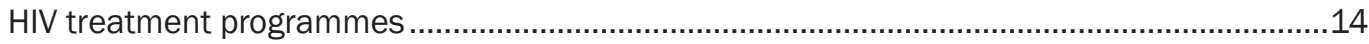

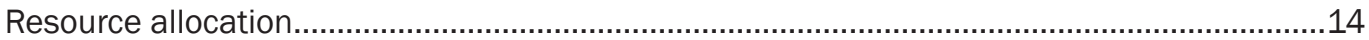

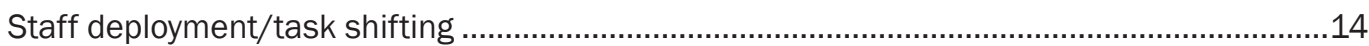

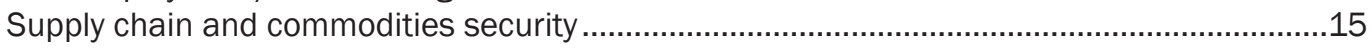

Pharmacovigilance/surveillance ................................................................................ 16

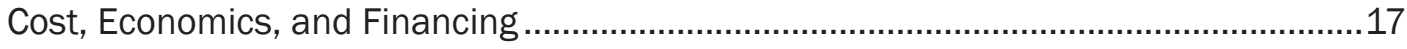

Short-term financing considerations for tenofovir gel introduction .........................................17

Long-term financing options for tenofovir gel .............................................................. 18

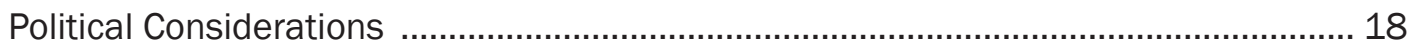

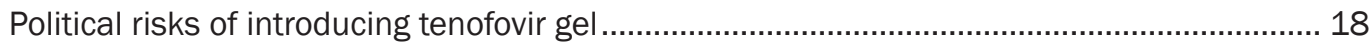

Engaging stakeholders .......................................................................................... 20

Champions and potential champions for tenofovir gel introduction ..................................... 20

Perspectives on opportunities missed by not introducing tenofovir gel ...............................21

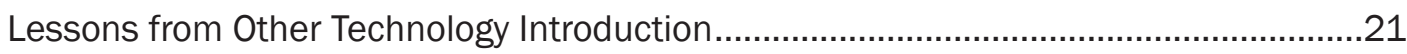

THE WAY FORWARD: PREPARING FOR INTRODUCTION........................................24

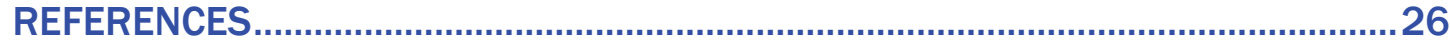

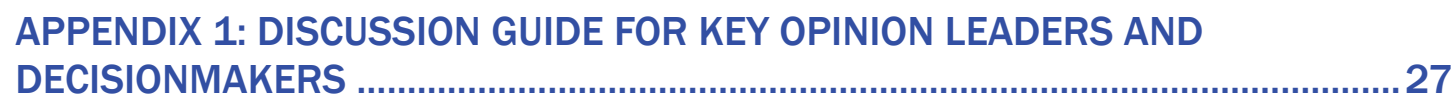

APPENDIX 2: ORGANISATIONS REPRESENTED ....................................................30 


\section{ACRONYMS}

\begin{tabular}{|c|c|}
\hline ANC & Antenatal care \\
\hline API & Active pharmaceutical ingredient \\
\hline ART & Antiretroviral therapy \\
\hline ARV & Antiretroviral \\
\hline $\mathrm{BCC}$ & Behaviour change communication \\
\hline CAPRISA & Centre for AIDS Programme of Research in South Africa \\
\hline $\mathrm{CHW}$ & Community health worker \\
\hline FACTS & Follow-on Consortium on Tenofovir Studies \\
\hline FGD & Focus group discussion \\
\hline FP & Family planning \\
\hline HPTN & HIV Prevention Trials Network \\
\hline HPV & Human papillomavirus \\
\hline HTC & HIV counselling and testing \\
\hline KOL & Key opinion leader \\
\hline MCAZ & Medicines Control Authority of Zimbabwe \\
\hline $\mathrm{MCH}$ & Maternal and child health \\
\hline MMC & Medical male circumcision \\
\hline $\mathrm{MOH}$ & Ministry of Health \\
\hline MRCZ & Medical Research Council, Zimbabwe \\
\hline MSM & Men who have sex with men \\
\hline MTN & Microbicides Trials Network \\
\hline NGO & Nongovernmental organisation \\
\hline NMTPAC & National Medicines and Therapeutics Policy Advisory Committee \\
\hline NRTI & Nucleotide reverse transcriptase inhibitor \\
\hline PEPFAR & U.S. President's Emergency Plan for AIDS Relief \\
\hline $\mathrm{PHC}$ & Primary health centre \\
\hline PICT & Provider-initiated counselling and testing \\
\hline РМТСТ & Prevention of mother-to-child transmission \\
\hline PPF & Prevention Partners Forum \\
\hline PrEP & Pre-exposure prophylaxis \\
\hline PSI & Population Services International \\
\hline RCT & Randomised controlled trial \\
\hline $\mathrm{RH}$ & Reproductive health \\
\hline SADC & Southern African Development Community \\
\hline SAfAIDS & Southern Africa HIV and AIDS Information Dissemination Service \\
\hline $\mathrm{SRH}$ & Sexual and reproductive health \\
\hline TASP & Treatment as prevention \\
\hline UNAIDS & Joint United Nations Programme on HIV/AIDS \\
\hline USAID & United States Agency for International Development \\
\hline VIA & Visual inspection with acetic acid \\
\hline VMMC & Voluntary medical male circumcision \\
\hline VOICE & $\begin{array}{l}\text { Vaginal and Oral Interventions to Control the Epidemic (Microbi- } \\
\text { cide Trials Network, Protocol 003) }\end{array}$ \\
\hline WASN & Women and AIDS Support Network \\
\hline WHO & World Health Organization \\
\hline
\end{tabular}




\section{EXECUTIVE SUMMARY}

Given the biological, economic, and sociocultural factors that limit women's ability to protect themselves against HIV, female-initiated prevention options, such as vaginal microbicides, are urgently needed. After more than 20 years of research, 1 percent tenofovir gel was the first vaginal microbicide to show promise in reducing risk of HIV infection (Abdool-Karim et al. 2010). A confirmatory trial (FACTS 001) is currently under way in South Africa, with results expected in late 2014. If results confirm tenofovir gel's effectiveness, a licensed product could be available by 2018 .

Efforts are under way to prepare for the introduction of tenofovir gel, should it be shown to be effective. In parallel with ongoing clinical research, governments and other stakeholders need information to guide decision-making regarding introduction of new HIV-prevention products, such as tenofovir gel. The United States Agency for International Development (USAID) spearheaded a global effort to prepare for tenofovir gel introduction. As part of this effort, the Population Council developed "A Toolkit for Strategic Decision-Making and Planning for Microbicides" to assist policymakers and programme managers in identifying opportunities for introducing tenofovir gel. A key step in developing the toolkit was testing it among key opinion leaders (KOLs) in several countries, including Zimbabwe.

Zimbabwe was chosen because it is one of the key countries in sub-Saharan Africa that has a generalised HIV epidemic and a commitment to microbicide introduction. In Zimbabwe, young women are disproportionately affected, with infection rates approximately three times higher for 20-24-year-old women compared with males of the same age (ZIMSTAT and ICF International 2012). Given the feminine face of the epidemic, clinical trials of vaginal microbicides have been conducted in Zimbabwe since the late 1990s (van de Wijgert et al. 2001; Obiero et al. 2012). Despite the challenging political and economic situation in Zimbabwe, clinical research is of the highest calibre, and many leaders in the microbicides field are based there.

This report describes the process and outcomes of a systematic inquiry among KOLs in Zimbabwe. These KOLs included a range of influential individuals who play a critical role in shaping public opinion and influencing policy, including senior Ministry of Health (MOH) officials, leaders of medical and pharmacy associations, civil society representatives, donors, and representatives of nongovernmental organisations (NGOs). The hope is that the timeframe between the completion of clinical trials and having a product available for women can be shortened by clarifying specific steps to be undertaken now and prioritizing those activities. Although the toolkit focuses primarily on tenofovir gel, the strategies identified may be applicable for the broader category of antiretroviral (ARV) drug-based prevention for women.

Most respondents were supportive of introducing tenofovir gel should it prove effective, with several caveats. Before a "go/no-go" decision can be made, policymakers will need to see compelling scientific evidence that supports tenofovir's introduction as an effective HIV-prevention method. Safety and efficacy were the chief concerns of all respondents. Some felt that efficacy levels should be benchmarked against medical male circumcision (MMC), while others noted the need to balance the level of efficacy with the need for a product that women themselves can use.

If tenofovir gel is proven efficacious, engagement of regulatory authorities and other groups will be needed. The Medicines Control Authority of Zimbabwe (MCAZ) is the key regulatory body responsible for product licensure, while the $\mathrm{MOH}$ is the custodian of overall HIV-prevention programmes. In addition, the National Medicines and Therapeutics Policy Advisory Committee (NMTPAC), which advises the government on drugs for use in the public health 
programme, will also play an important role. There were mixed views on the need for technical guidance from external agencies such as the World Health Organization (WHO).

The economic climate in Zimbabwe was viewed as a significant barrier to government financing of tenofovir gel introduction. Thus, help from external agencies would be needed to support both programming and subsidizing product cost, at least initially. Commodity security was seen as a key element of any introduction agenda, with all parties needing to work together to ensure that supply issues are addressed for long-term sustainability.

Respondents had varied and nuanced analysis of potential priority user groups for tenofovir gel. From a public-health and cost-effectiveness standpoint, women at highest risk (such as young women, sex workers, and women with multiple partners) were viewed as key groups to be targeted. Yet, from a practical standpoint, it was also recognised that it can be difficult to identify or reach these women, and other women (including married women) may also be at high risk. There were mixed opinions as to the relevant merit of targeting sero-discordant couples.

Most KOLs suggested that tenofovir gel be made available in both the public and private sectors, and that it be integrated into existing programmes, particularly reproductive health and HIV-testing programmes. Demonstration projects in Zimbabwe were underscored as critical for measuring product uptake/adoption and for identifying the most effective strategies for tenofovir gel delivery. Recognizing the need for periodic HIV testing to safely deliver tenofovir gel, concern was expressed on the one hand that this testing will be an additional burden to

A number of suggestions were made for preparing for the introduction of tenofovir gel:

Work with Prevention Partners Forums (PPFs) to ensure broad stakeholder involvement;

- Engage the MCAZ and the MOH now to accelerate regulatory and programmatic processes should tenofovir gel be proven efficacious;

- Conduct workshops with providers to explore service delivery options and programme design;

- Cultivate champions for tenofovir gel;

- Develop provider training plans and materials; inform and educate health care providers and provider networks;

- Draft operational plans for demonstration projects for tenofovir gel service delivery;

Identify effective communication among product developers, clinical trial researchers, and other interested parties so that updated information and the status of trials will be shared in a timely manner. the already overtaxed health system, yet may also have a positive impact, because providers will have something to offer women who test negative.

Champions were considered important for this new type of product, although respondents felt such people do not currently exist for tenofovir gel or ARV-based prevention. Several individuals who are viewed as champions of women's rights and HIV prevention and treatment were identified as potential advocates who could be cultivated to play this role.

The interviews with KOLs prompted thoughtful discussions about the challenges and possibilities of introducing tenofovir gel. Although the KOLs identified a number of complexities with providing tenofovir gel, overall they were committed to doing so, pending evidence that it would be effective in reducing the risk of HIV and recognizing the lack of HIV-prevention options currently available to women. 


\section{INTRODUCTION}

Zimbabwe, with an estimated population of 12.7 million people, is among the countries in sub-Saharan Africa most affected by the HIV and AIDS epidemic. In 2011, the estimated HIV prevalence among adults 15 years and older was 14.9 percent, a total of 1.2 million adults and children were living with HIV and AIDS, and of those approximately 62,000 were newly infected (UNAIDS 2013). Zimbabwe is described as having a generalised heterosexually driven HIV epidemic, which accounts for 92 percent of the HIV infections (ZIMSTAT and ICF 2012; UNAIDS 2013).

Zimbabwe, like many other African countries, has seen a tremendous shift in the HIV landscape in the last decade, particularly with respect to HIV prevalence (Hargrove et al. 2011). This shift parallels global efforts to reduce the incidence of HIV, especially among the most vulnerable populations. Local efforts to reduce the impact of HIV have included scaling up treatment, access, and HIV-prevention programmes, particularly behavioural interventions such as condom use and reduction of sexual partners. Yet many people, especially women, are still at high risk, and efforts to identify and implement additional HIV-prevention options remain critical.

After nearly 20 years of microbicides research, 1 percent tenofovir gel is the first vaginal microbicide to show promise. Tenofovir disoproxil fumerate (Viread) is a nucleoside reverse transcriptase inhibitor (NRTI) that has been used for HIV treatment since its approval by the US Food and Drug Administration as an oral tablet in 2001 (US Food and Drug Administration 2013). Since 2011, Zimbabwe has been scaling up use of tenofovir-based regimens as firstline therapy for adults infected with HIV (IRIN News 2011). In parallel with its development for treatment, tenofovir has been tested for HIV prevention both as a tablet (Viread) and as a vaginal gel. A randomised, placebo-controlled, double-blind trial, known as CAPRISA 004, demonstrated that women assigned to use 1 percent tenofovir gel before and after sex (BAT-24) had a 39 percent lower risk of HIV infection compared with women in the placebo arm (AbdoolKarim et al. 2010). Tenofovir gel was even more protective for women who reported using gel in more than 80 percent of sex acts; among these high adherers, reduced risk of HIV was 54 percent (Abdool-Karim et al. 2010). Tenofovir gel was also tested in the Microbicide Trial Network's VOICE trial, in which women were randomly assigned to one of five daily-dosing regimens: 1 percent tenofovir gel, placebo gel, Viread (oral) tablet, Truvada (oral) tablet, or placebo tablet. None of the products were effective in reducing the risk of HIV acquisition, although product adherence was low in all arms (MTN 2013). FACTS 001, a confirmatory trial of tenofovir gel using the BAT-24 dosing regimen from CAPRISA 004, is currently under way in South Africa, with results expected in 2014 (FACTS Consortium 2013).

As research continues, policymakers and other stakeholders need information to guide decision-making regarding introduction of new HIV-prevention products, including tenofovir gel. A number of efforts are under way to compile this information. For example, USAID spearheaded a global effort to develop a strategic framework for tenofovir gel introduction. As part of this plan, the Population Council developed "A Toolkit for Strategic Decision-Making and Planning for Microbicides" to assist policymakers and programme managers in identifying strategic opportunities for introducing microbicides, including tenofovir gel. The toolkit includes three related components: Module 1 (Landscape Analysis), Module 2 (Discussion Guide for Key Opinion Leaders), and Module 3 (Program Planning Guide). A key element of the toolkit development process has been to test it among KOLs in several countries, including Zimbabwe.

Zimbabwe is one
of the countries
in sub-Saharan
Africa hardest hit
by HIV and AIDS,
with a commitment
to microbicides
introduction.

Zimbabwe is one the countries in sub-Saharan Africa hardest hit by HIV and AIDS, to microbicides introduction. 
Zimbabwe was chosen because it is one of the countries in sub-Saharan Africa that has a generalised HIV epidemic and a commitment to microbicide introduction. In Zimbabwe, young women aged 20-24 are disproportionately affected, with infection rates approximately three times higher than in males of the same age (ZIMSTAT and ICF 2012). Given the feminine face of the epidemic, clinical trials of vaginal microbicides have been conducted in Zimbabwe since the late 1990s (van de Wijgert et al. 2001; Obiero et al. 2012). Despite the challenging political and economic situation in Zimbabwe, clinical research is of the highest calibre, with many leaders in the microbicides field based there. This report describes the process and outcomes of a systematic inquiry among KOLs in Zimbabwe. These KOLs included a range of influential individuals who play a critical role in shaping public opinion and influencing policy, including senior $\mathrm{MOH}$ officials, leaders of medical and pharmacy associations, civil society representatives, donors, and representatives of NGOs. 


\section{STUDY DESIGN AND METHODS}

The overarching objective of this study was to test Module 2 of the toolkit. This was accomplished through in-depth interviews with KOLs to gather their perspectives on critical policy and programmatic issues outlined in the toolkit. KOLs, who include a range of influential individuals (e.g., senior $\mathrm{MOH}$ officials, leaders of medical and pharmacy associations, civil society representatives, donors, representatives of NGOs), play a critical role in shaping public opinion and influencing policy. A qualitative study of purposively sampled KOLs in Zimbabwe was undertaken in the last quarter of 2012. Individuals in leadership roles were identified to capture multiple perspectives that reflect policy, programme, service delivery, and civil society positions.

In-depth interviews were conducted by Population Council staff and consultants using a standardised discussion guide covering policy, regulatory, and programmatic themes. A roster of $20 \mathrm{KOLs}$ was developed, and interviews of approximately 1 to $1 \frac{1 / 2}{2}$ hours were conducted with each respondent (see Appendix 1). Interviews were documented by audio recording and with handwritten notes. Each respondent provided written informed consent and was told that their statements would not be attributed, in order to preserve confidentiality. Interviews were analysed thematically based on the interview guide through an iterative process among the research team. 


\section{FINDINGS AND KEY INSIGHTS BY THEMATIC AREA}

\begin{abstract}
Respondents grappled with the level of efficacy necessary to overcome concerns about risk compensation and resistance.
\end{abstract}

\section{Scientific Evidence on Tenofovir Gel}

\section{Efficacy}

Level of efficacy required to approve or recommend gel: The consensus was that the most important information for making a decision about whether or not to introduce tenofovir gel is whether it works to prevent HIV. A few respondents said that any level of efficacy would be sufficient, because currently there is no option that is within women's control; even if women know that they are not 100 percent protected, any protection is better than none. A minority $(6 / 19)$ felt that tenofovir gel would not be worth introducing unless it is at least 50 to 60 percent effective, comparable to male circumcision. Some said that the 39 percent level of efficacy shown in the CAPRISA 004 trial would be sufficient, although there were simultaneous concerns about condom substitution, similar to concerns that men who have been circumcised may use condoms less frequently. If tenofovir gel offers only partial protection, women might be at increased risk of HIV infection as a consequence of "risk compensation," an increase in risk behaviour such as increasing number of partners or decreasing condom use. One person interviewed said, "I would really want to see some data that says this [tenofovir gel] is not backfiring and doesn't lead to risky sexual behaviour. In my experience from the nevirapine studies, concepts of risks and percentages are not easily grasped in a community level." Therefore, many respondents felt that messages about partial efficacy must be carefully crafted when tenofovir gel is introduced.

Another concern related to tenofovir gel being partially effective for HIV prevention is that tenofovir is the same active drug that is used to treat AIDS as the first-line regimen in Zimbabwe. As one key opinion leader noted,

This is the drug that we are using as first-line treatment, the best drug we have, and I tend to worry about dishing it out in small doses.

Type of data needed: There was widespread agreement that the key data for decision-making are results from randomised controlled trials (RCTs). Several respondents noted that they did not have information about the ongoing confirmatory trial (FACTS 001), and felt it would be helpful to have regular updates for planning purposes. In addition to the RCTs, many believed it would be important to implement local demonstration projects before making decisions about broader introduction in Zimbabwe.

There was sensitivity to government's need to prioritise HIV-prevention strategies, with considerable discussion about importance of cost-effectiveness data. Several KOLs stressed the value of data on cost per HIV infection averted that would likely be generated using mathematical modelling.

Some respondents suggested that clinical trial results should be communicated first to highlevel ministers, obstetricians/gynaecologists, and international and local NGOs' implementing partners. Specific approaches could include a joint consensus process and Prevention Partners Forums (PPFs). 


\section{Safety}

The KOLs interviewed often discussed efficacy and safety together, because both are critical for making decisions regarding country-level adoption; however, there was a range of views on what type of safety data is most important. The key issues raised are described below.

Pregnancy and breastfeeding: The majority of KOLs mentioned the importance of tenofovir gel for HIV prevention in pregnant women given that pregnancy is a particularly vulnerable time. There were mixed opinions, however, about whether data on safety in pregnant women would be necessary before licensure. Some said data on safety in pregnant women should not be required prior to licensure, while others felt that it would be critical to show safety in pregnant women (and fetuses) before licensure. Much of this concern centered on women who might use tenofovir gel without knowing they are pregnant. One KOL suggested safety in pregnancy could be studied in a Phase 4 post-marketing study. A few mentioned the need for data demonstrating safety of tenofovir gel during breastfeeding, while others noted that HIV-positive women who are breastfeeding are already taking tenofovir for treatment.

Resistance: Potential resistance was raised as an issue by most respondents, with some emphasizing that it would be important to know the extent to which topical tenofovir is absorbed systemically. If tenofovir is not systemically absorbed, these KOLs felt there would be fewer concerns about resistance. A few respondents already assumed that topical tenofovir would not be absorbed systemically and were therefore not concerned about potential resistance. Some respondents linked their concerns about potential resistance to the relatively low (39 percent) level of efficacy of tenofovir gel found in the CAPRISA 004 trial, noting that they would be less concerned about resistance with a highly efficacious product.

A number of respondents noted that the current HIV testing systems in Zimbabwe are not sufficient to ensure ongoing HIV testing and monitoring, with a few suggesting that resistance would not be as great a concern if these systems were adequate. Other concerns about potential resistance related to the gel containing only one active drug whereas three drugs are needed to avoid resistance among people on antiretroviral therapy (ART).

Finally, some respondents expressed concern about people developing resistance if they used tenofovir gel for prevention, later sero-converted, and then were prescribed oral tenofovir (Viread) for treatment. Therefore, it will be important to determine whether someone who used tenofovir gel for prevention but later sero-converted could use tenofovir for treatment, as Viread is part of the first-line treatment regimen in Zimbabwe. One KOL suggested that if concerns about resistance are a significant barrier to approval, studies in animals could potentially be included in the regulatory review if sufficient human data on resistance is not yet available.

Safety in different populations: Most respondents said that tenofovir gel needs to be safe for women, with some recommending separate safety studies in adolescents. Others noted it would be good to test tenofovir gel in men who have sex with men (MSM). The predominant sentiment seemed to be prioritizing women, as indicated by a respondent who said, "I think it's a women's product and as such should be effective among this population group. The rest is an added bonus."

Impact on fertility: Most KOLs were not concerned about (or did not mention) fertility as an issue, although two noted that any impact on fertility would severely limit uptake of an HIV-prevention product. 
I would like a dual product that has a temporary effect on fertility [contraception] and can be used for HIV as well. It would be interesting science. But any hint that a product that is intended for HIV prevention affects [long-term] fertility would be a potential disaster.

Dry sex: One respondent spontaneously mentioned ensuring safety for women who practice "dry sex," noting that although efforts have been made to educate people about the potential harm from inserting products or substances to dry the vagina, there are still pockets of the community where dry sex is practiced. Therefore, this respondent felt it would be important to know whether tenofovir gel would have any potential adverse effects if used by women practicing dry sex.

\section{Adherence and acceptability}

Most of those interviewed acknowledged that data on adherence and acceptability from the RCTs are important but that there is not necessarily a connection between whether and how gel is used in a trial and in "real life" settings. Some noted that adherence and acceptability are important from a public health perspective, though not as critical as safety and efficacy from a regulatory perspective. Many noted that user perspectives would be critical for estimating demand.

Several types of studies were suggested to assess acceptability and feasibility in the Zimbabwean setting, including focus group discussions (FGDs) among women and male partnerseven while waiting for the confirmatory results from the ongoing trials. FGDs could explore key issues such as how well people understand partial effectiveness, whether they would be interested in tenofovir gel, and how best to market it to be acceptable to men. KOLs emphasised the need to gather men's perspectives early, to explore how people view the gel in areas where dry sex is practiced, and to include both rural and urban perspectives.

\section{Regulatory Review and Licensure}

Several bodies are involved in the regulatory framework for tenofovir gel in Zimbabwe. These include the Medicines Control Authority of Zimbabwe (MCAZ), the National Medicines and Therapeutics Policy Advisory Committee (NMTPAC), and the Ministry of Health (MOH).

Some of the respondents assumed that MCAZ was already involved in reviewing the data from the clinical trials. All agreed that it is critical to involve MCAZ as soon as possible, before the confirmatory clinical trial is completed, to speed the approval process in Zimbabwe. One respondent suggested that MCAZ also needs to be kept informed to begin planning a Phase 4 post-marketing study. The NMTPAC was described as the body that has the mandate to advise the $\mathrm{MOH}$ on the introduction of new drugs into Zimbabwe. Ad hoc expert committees are convened to review data and make a recommendation to NMTPAC as to whether or not a new drug should be introduced. The NMTPAC then makes a recommendation to the $\mathrm{MOH}$, which ultimately determines whether a drug will be made available in Zimbabwe. Licensure by MCAZ is an essential step before the $\mathrm{MOH}$ draws up guidelines for use and distribution. Respondents explained that MCAZ and the $\mathrm{MOH}$ generally convene stakeholder meetings in preparation for drafting such guidelines.

One respondent explained that there is a tax on imported active pharmaceutical ingredients (APIs), which can greatly affect licensure and marketing of a product in Zimbabwe. Another 
noted that the Southern African Development Community (SADC) and South African manufacturers will need to play a role in regulation and manufacturing issues. Further follow-up is needed to identify which specific issues these different entities address.

Respondents all saw MCAZ as the critical review body for licensing a product in Zimbabwe. Opinions were mixed on the relevance of WHO guidance for the review process in Zimbabwe. Some felt WHO guidance would be essential for local licensure and approval, whereas others felt WHO guidance would be useful but not necessary. A minority said WHO guidance would be irrelevant and all decision-making should be guided by the MOH and MCAZ. Several mentioned additional technical guidance that has been helpful in the past when introducing new drugs or procedures, including from the Global Fund, the Population Council, and FHI360. Only one KOL mentioned the US Food and Drug Administration, which was in the context of prequalification for Global Fund support.

\section{Intended Users}

\section{Who would benefit most from the introduction of tenofovir gel?}

From a public health and cost-effectiveness standpoint, respondents said it would make the most sense to focus on women who are at the highest risk: young women, sex workers, and women with multiple partners or whose partners have multiple partners. However, from a practical standpoint, most said this would be very difficult to do because it can be hard to identify or reach women in these categories. One respondent noted that "fundamentally, every woman who perceives themselves at risk should have access." Another respondent said tenofovir gel would be most useful for women at unknown or theoretical risk (i.e., not knowing their partner's status, not knowing if their partners have other partners) versus those at known risk (i.e., in a sero-discordant relationship). Several KOLs suggested that modelling would offer further insights to inform prioritization of user groups and recommendations for specific circumstances.

Sero-discordant couples: There were mixed views about focusing on sero-discordant couples. Some respondents saw sero-discordant couples as a clear priority but had reservations about how to identify such couples. One respondent noted that tenofovir gel would be particularly useful for sero-discordant couples who wanted to conceive. Some respondents wondered if, for example, an HIV-positive woman could use tenofovir gel to protect her partner if she was not yet eligible for treatment, whereas others did not think sero-discordant couples should be prioritised, specifically because they are at high risk and tenofovir gel is only partially effective. These respondents believed it was more appropriate for the infected partner to be on treatment, which would be much more effective in reducing transmission to the uninfected partner. A few respondents raised concerns about resistance, particularly if the HIV-positive partner was already undergoing treatment.

Adolescents and other young women: The majority of those interviewed identified young women as being at high risk, with HIV incidence highest among the 20-24-year-old age group, making them a logical priority for tenofovir gel. However, several noted that it is important to ensure that tenofovir gel is safe for young women before it is widely promoted to them. Given that pregnancy rates are also high in this age group, there was also some concern about safety in pregnancy and any long-term effects on fertility (as noted above). Several mentioned prioritizing young women at tertiary institutions who are at high risk of HIV and could be reached by services in those settings. One explained that while women's enrolment

Tenofovir gel would
benefit any woman
who perceives
herself to be at risk
of getting HIV.

Tenofovir gel would

benefit any woman who perceives

of getting HIV. 
in universities has grown, there is no support for accommodation or personal expenses, which puts young women at risk. Finally, one person suggested that young people be sought out because they are generally more open to new ideas and innovations.

Married women: A number of respondents noted that married women are exactly the constituency for tenofovir gel because so many HIV infections occur in married couples in Zimbabwe. Despite there being a high need among married women, several pointed out the challenges targeting a group with diverse risks and needs. First, it is difficult for service providers-and for married women themselves-to identify who is at risk, because women may not know they are involved in a multiple concurrent partnership. Women whose partners work far away from home may not want to acknowledge that they are at risk-either from their partners having multiple partners or because they themselves have other sexual relationships. In communities where a high proportion of women have partners who are away, it was noted that health workers should not ask why women are coming for services.

Second, it can be difficult for women to introduce something new into their relationships. One respondent said:

Tenofovir gel could be used by women if they have discussed it with their partners. Some couples have problems even if the partner introduces the mere fact that they want to use something-this may be seen as an accusation.

Echoing many other discussions about gel use, another respondent noted that a gel that could be used discreetly may be fine, but if a man discovers the gel it could lead to problems. A few individuals thought that in areas where dry sex is the cultural norm, it would be more difficult for women to use the gel.

Women with multiple partners: Several KOLs talked about a group of empowered, high-income women who have multiple partners because they can afford it. They referred to this group of women as "sugar mummies" and said they would be an ideal target group for tenofovir gel. One caveat would be that these women would need to self-identify because it is culturally unacceptable for women to have multiple partners, so women might not be willing to acknowledge or report to health care workers that they are at risk in this way.

Women who have infrequent (but risky) sex: Respondents thought it would be difficult to identify women who fit into this category and felt it would make more sense to target women more broadly. Some, however, were concerned about how effective tenofovir gel would be for women who used it intermittently. Issues raised included:

More information is needed about the BAT-24 regimen and the implications of using the regimen in an on-and-off pattern.

- In particular, when young women start becoming sexually active, what happens if they use the gel on and off? What if a young woman uses the gel once and then again three months later? Does using tenofovir gel in an inconsistent pattern have an impact on effectiveness? Resistance?

One respondent thought that the BAT-24 regimen would be particularly good for women who have sex infrequently and that they would be more likely to adhere to the regimen than people having sex more regularly.

Sex workers: The respondents were almost unanimous in agreeing that sex workers would benefit most from the introduction of tenofovir gel. One respondent noted that "sex workers 
have to charge less with condoms, so using the gel would provide protection without the clients knowing." Another said, "There is current hopelessness among sex workers who feel that they will inevitably get infected with HIV. This [tenofovir gel] is a tool that will help them prioritise their health."

Operations research among sex workers was recommended because they are an identifiable population with partners who are both HIV positive and negative. However, despite recognizing sex workers as an important target population, respondents also cautioned against only targeting sex workers, noting that such an approach would stigmatise the product for anyone else. One KOL said, “...my experiences in dealing [with] and rolling out female condoms was that they [female condoms] were stigmatised by rolling them out there [to sex workers], so we can target this group [sex workers] but proceed with caution." Another respondent thought sex workers were not the highest risk group, saying, "I don't think they [sex workers] are as vulnerable as married women, and [targeting sex workers] stigmatises the product."

\section{Where should tenofovir gel be offered?}

Sector: Respondents said tenofovir gel should be available in both the public and private sectors and assumed that distribution would start through primary health centres (PHCs) and NGOs, like the New Start Centres operated by Population Services International (PSI). Some felt that once there was sufficient pharmacovigilance data, tenofovir gel could be available more broadly, including through pharmacies and even supermarkets. A few noted that it would be important to introduce tenofovir gel in both the public and private sectors simultaneously, because not all women (sex workers, in particular) access public-sector services. One respondent from the $\mathrm{MOH}$ said:

We seem to have a rigid public health approach and many things need to change for effective introduction of new technologies. I am worried about adding more things to a dead horse that may not wake up. Nongovernment organisations and [the] private sector would do this better, but government maintains overall responsibility.

Service delivery settings: Introduction was recommended through both family planning/ sexual and reproductive health (FP/SRH) services and HIV-prevention programmes. The most natural fit for tenofovir gel seemed to be family planning clinics in the public sector and well-woman clinics in the private sector, as expressed by respondents who said, "Currently the family planning facilities would offer the best value for the money" and "The best entry point is for clients who come to the family planning services, as we know they are sexually active and also at high risk for HIV infection." One respondent noted that "family planning centres that exist in each region could also be used as initial sites, such as Lister House in Bulawayo and Spielhaus in Harare." Another KOL explained the importance of well-woman clinics in scaling up new technologies, saying "We are rolling out VIA [visual inspection with acetic acid for cervical cancer screening] throughout the country and are seeing the need to ensure wellwoman clinics in Zimbabwe."

Placing tenofovir gel within primary health or SRH services was seen as less stigmatizing and more routine, even if repeat HIV testing was involved. One respondent claimed, "Reproductive health is the best delivery channel with less stigma." Another noted that tenofovir gel "could also be incorporated into the family planning facilities in that people come often, but it entails testing every time someone comes and this has cost implications since you have to keep on testing." 
Several KOLs noted that women generally have their first HIV test in the context of antenatal care (ANC), making it an ideal place for tenofovir gel delivery. Other suggestions included integrating tenofovir gel into well-baby and immunization visits. Respondents from the $\mathrm{MOH}$ talked about improving the links between SRH and HIV prevention. One noted that, for example, in Tanzania, PMTCT is part of reproductive health programmes, whereas in Zimbabwe it is currently linked with paediatric programmes. One respondent said:

I would like to see an integrated primary health programme that has a reproductive health message. This is where tenofovir gel would fit. Currently the family planning setup is the best one for tenofovir gel.

Another respondent mentioned the potential for delivery in schools, although also noted that this could be controversial.

Most schools have a health desk and school nurses-they should have access to prevention. There are existing programmes in high school for HIV education, but we need to offer more, such as testing and other prevention.

A number of people noted, however, that it would be easier to work with the $\mathrm{MOH}$ than the Department of Education.

Many KOLs also recommended that tenofovir gel should be a preventive health offering in primary care facilities and that government-introduced provider-initiated counselling and testing (PICT) is a good entry point. They explained that nurses can now provide ART and it should be the same for tenofovir gel, making it a reasonable product to distribute at the PHC level.

Some respondents also talked about ultimate distribution through community outreach programmes, including by community health workers (CHWs) who now supply malaria treatment. However, one cautioned,

We need to ensure that there is initially enough instruction for them [women in the community]. While it is attractive to get the product out there in droves, we need someone to explain its usage, especially in the rural area, and someone who can explain efficacy.

One KOL wondered if tenofovir gel could be available for free in local pharmacies with a message like "taking your free vitamins." Yet another said that if tenofovir gel were to be distributed in pharmacies, packaging should contain clear instructions.

Programmes: Promoting tenofovir gel as part of an HIV-prevention package and not a standalone programme, in the way the voluntary medical male circumcision (VMMC) programme has been rolled out, was emphasised. One KOL noted that the $\mathrm{MOH}$ is currently working on a strategy for integration of HIV and SRH and that they are looking for opportunities. If an HIV prevention product also prevented pregnancy, then it could be offered in RH settings as well as HIV settings and would be available for a wider range of potential users. Two respondents emphasised the importance of working with men's groups and political leaders to get men on board more broadly. One said it will be important to gather input from men on the way to promote tenofovir gel, such as a "hygiene product that improves sex and keeps you and your loved one safe" versus strictly as an HIV-prevention product.

One respondent talked about the current work of the "Combination Prevention Think Tank," which recognises that multiple methods are available and that work needs to be done to develop communication strategies about how to position these methods to be used together. One KOL suggested that because behaviour change is difficult, medical interventions are 
more likely to be successful, noting that tenofovir gel would be the third evidence-based prevention programme (in addition to VMMC and PMTCT). Another respondent felt that, assuming 50 percent efficacy, tenofovir gel would be a good option while waiting for intravaginal rings, presumed to be more efficacious for HIV prevention or that would prevent both HIV and pregnancy. Tenofovir gel was not viewed as a replacement for condoms or treatment-asprevention, given cost and adherence issues. Several KOLs noted that it would be beneficial to learn from the distribution of antiretroviral therapy, with some advocating that tenofovir gel actually use the same HIV treatment delivery channels.

Condom promotion programmes: Most KOLs thought tenofovir gel would fit well with condom promotion programmes, noting that even though condoms are nearly 100 percent protective, they are not used 100 percent of the time, so tenofovir gel would give people options. However, some cautioned against promoting condoms and tenofovir gel together for several reasons.

One person noted that, "Men don't like condoms and this [promoting tenofovir gel with condoms] would dilute the message on condoms" and suggested that tenofovir gel be promoted as a reproductive health tool "so that it appeals to a certain mindset." Distributing tenofovir gel may not be feasible where condom distribution is largely done by peer educators, because tenofovir gel requires more sophisticated information provision and medical supervision.

Several respondents noted that female condoms are also an important part of HIV prevention. One said, "Let's not forget that we need to couple this [tenofovir gel] with female condoms as well." Another felt that the gel would have benefits over female condoms, saying,

With female condoms, you still need men on board and men don't like women calling the shots; the gel could give more power to women because men don't need to do anything, whether or not they know about the gel.

One person also talked about pricing of female-initiated prevention versus male condoms, noting that it costs US $\$ 1.00$ for two female condoms, whereas for the same price, one can get three male condoms, which are also widely available for free.

Voluntary medical male circumcision (VMMC): There was a sense that VMMC services should be targeted to men and tenofovir gel provision targeted to women, and that trying to combine services in one setting would dilute them both. Some respondents, however, envisioned a "family health" approach where VMMC would be offered to men and neonates, and tenofovir gel would be offered to women. One said, "I am a champion for VMMC and think it's easier to get women there by selling family health" (male circumcision for men, neonatal [circumcision] for the infant, and microbicides for the woman).

One respondent talked about the inherent difference between VMMC and tenofovir gel that might make it challenging to provide them together. VMMC is a one-time medical procedure with fixed costs over a fixed period of time, whereas the costs of tenofovir gel are ongoing for an indefinite period of time. In addition, it would be feasible to estimate the cost of VMMC based on the number of males who are not yet circumcised, but it would be much more difficult to estimate the amount of tenofovir gel needed because several variables are unknown (the number of women at risk, frequency of sex, rate and degree of uptake). These critical differences result in differing implementation scenarios. VMMC could be viewed as "get in and get out," with the $\mathrm{MOH}$ contracting private organisations to implement a one-time programme, whereas tenofovir gel would require the $\mathrm{MOH}$ to find a way to sustain service delivery over time, with demand increasing (or decreasing) making it much more difficult to estimate demand, programmatic needs, and costs. 
Oral pre-exposure prophylaxis (PrEP): Currently, oral PrEP is not available in public sector programmes in Zimbabwe and guidelines are being developed.

PMTCT: Some of the respondents said PMTCT would be a good programme in which to incorporate tenofovir gel because it is one of the strongest service-delivery channels for HIV prevention. KOLs noted, however, that people coming for PMTCT are already infected and that there is greater need to provide tenofovir gel before and during ANC, before women become infected. One KOL wondered if tenofovir gel could be used for HIV-positive women if they are not already on ART, or for prevention of re-infection for HIV-positive women who are pregnant or breastfeeding.

Behaviour change communication (BCC): The KOLs interviewed felt that tenofovir gel would fit nicely into BCC campaigns, which many felt had worked well in Zimbabwe. Some felt that the campaigns would need to target men and adolescents to be successful in promoting tenofovir gel. Several said the context of the messages should be of overall health and well-being, such as good hygiene or improving sex, rather than a medical intervention designed for disease prevention. One respondent said:

A product like this can be an opportunity to balance the social approaches to prevention. The tenofovir gel may have followed a scientific process that is rigorous, but its implementation, as a product of intimacy, is a social agenda that involves behaviour change.

\section{Impact on Health Systems}

Although the KOLs interviewed identified weaknesses in the current health system, most indicated that the problems should not impede introduction of tenofovir gel.

Tenofovir gel introduction should not negatively affect the health systems if gradually introduced in pilot phases. We should worry about acceptability more than burdening the health systems.

Respondents emphasised that introducing tenofovir gel should not be isolated but rather be part of a health systems and development agenda.

We need to view this as part of development. If Zimbabwe stays the way it is, where bread and butter issues are not addressed, we will not address HIV.

Introduction of tenofovir gel could both stress and reinvigorate existing HIV testing programmes.
Respondents felt that introducing tenofovir gel would not pose a significant burden on the health system overall. One emphasised that up-front costs and activities would likely be more substantial than ongoing efforts. Several noted that the impact would depend on where tenofovir gel is introduced, explaining that programmes are currently highly vertical, with separate programmes for VMMC, PMTCT, and other HIV-prevention interventions. Ensuring that tenofovir gel is integrated into existing services from the outset will be important, since these different vertical programmes are competing for the same resources. One respondent suggested that tenofovir gel could be introduced as part of PICT. Doing so would require building the capacity of PHCs to include tenofovir gel as part of provider-initiated testing. Several felt that as long as providers are trained, facilities will not be overwhelmed.

Some KOLs viewed the introduction of tenofovir gel as an opportunity to strengthen health systems: "If the gel comes with [a] health systems strengthening component, this will help the whole system, and we need that [approach instead of] coming in isolation, just adding the gel without a strategy. We need a strategy with a health systems strengthening component." 
One person from the $\mathrm{MOH}$ said, "Before we even talk about tenofovir gel, we need to put the health system right, especially commodity security and quality of services. We are dealing with clients and they do need information that the system has been too arrogant to produce."

The following were noted as critical issues to address up-front:

- Supply chain, including the size and shelf life of the product, and procedures for ordering.

- Estimating demand to prevent facilities from running out of supplies, despite the difficulty of predicting consumption.

- Guidelines and algorithms from the $\mathrm{MOH}$.

Training procedures.

However, one respondent was deeply concerned about the impact on health systems, saying,

For me it's a health systems conversation more than anything else. We need to ensure that Zimbabwe revives its health care system so that it responds to the current and future plans, say for example on elimination of mother-to-child-transmission. Currently we are struggling in many respects.

\section{HIV testing programmes}

HIV counselling and testing (HTC) programmes were seen as a good entry point for tenofovir gel because they are already set up for a large volume of HIV testing. One example is New Start, a nationwide network of sites providing HTC services, run by PSI in Zimbabwe. The introduction of tenofovir gel was also seen as an opportunity to revitalise or enhance existing HTC programmes. Currently, when women test negative, there is nothing to motivate them to come back for repeat testing, and tenofovir gel might encourage ongoing testing.

[Tenofovir gel] probably would help in the [HTC] programme since the testing would be accompanied by something that women can use.

There was some discussion about the success of rolling out PICT at maternal and child health $(\mathrm{MCH})$ clinics, in-patient hospitals, and to women in labour and delivery, and some suggested that tenofovir gel would be offered as part of PICT and couples counselling, where services are free. One KOL pointed out that "because of user fees, there is not a lot of appetite to go to health facilities," whereas HIV testing and counselling centres are free.

Despite the feeling that tenofovir gel could reinvigorate HTC programmes, a number of KOLs felt that the current programmes would need to be revamped to support an influx of people wanting to be tested. Some also talked in depth about how the monthly testing in the trials could not possibly be supported in service delivery.

I think this [HIV testing] is one of the biggest challenges for me. How do we test every woman who will use the gel at least four times or say twice a year to be conservative when we can't test 50 percent of the population once in their lifetime right now? I think this will place a huge strain on the testing facilities. We need to think of quicker, better methods for HIV testing. We have had issues in the past on these testing services.

Operations research is important. Women were having monthly testing in the trials. We need nurses to distribute [tenofovir gel] and less frequent testing. We don't want impediments for monthly testing. This is genital tract with low absorption, therefore less chance of resistance. 
Currently people test [for HIV], but there is no structure for retesting. There is no policy guideline on retesting of HIV negatives, for example, coming for SRH services. Some women come [to get pill supplies] for about six cycles; injectables after three months. Implants-you won't see them afterwards, unless there are side effects. Most [women] come after six months, so that might be feasible for a retesting interval.

One KOL said, "There is no excuse for not introducing the product unless there are safety and efficacy concerns." Another summed up by saying, "The health systems debate should not stop us from introducing a new product if it's going to help the system.... Women need options."

\section{HIV treatment programmes}

The majority of KOLs did not see that tenofovir gel would have a negative impact on HIV treatment programmes. Most felt that tenofovir gel would be part of preventive services and not delivered where treatment is delivered. A few noted that tenofovir gel could have a positive indirect impact on treatment programmes if fewer people became infected and therefore fewer people required treatment. There were some concerns, however, that tenofovir is the same active drug used in first-line treatment. Issues of cost (making decisions about how resources should be spent) and resistance were discussed, particularly whether people using tenofovir for prevention who became infected could use tenofovir for treatment.

\section{Resource allocation}

Concerns about limited resources were pervasive, especially given the current economic situation in Zimbabwe. Although the government leads HTC, PMTCT, and VMMC programmes, all are donor funded. One respondent felt that the government would not prioritise microbicides in the next round of Global Fund funding, explaining that if the government has to choose between introducing microbicides or the human papillomavirus (HPV) vaccine, they would choose the vaccine, especially if the microbicide is only 39 percent effective. Indeed, many KOLs linked resources with a product's efficacy. One noted that the emphasis now is on VMMC, which is 60 percent effective, and it would be unlikely for the government to shift resources to anything less effective. One respondent said:

Resources will always be found if we have a compelling case. Our prevention budget is low, I agree, but if a product shows some cost-effectiveness, we can find money to reprioritise. Decision-making for government is based on many factors-health systems factors are certainly not an excuse for not introducing tenofovir gel.

The discussion of resource allocation also included staffing. KOLs were fairly unanimous that introducing tenofovir gel would not be financially or logistically feasible unless nurses could distribute it.

\section{Staff deployment/task shifting}

Most KOLs interviewed felt that introduction of tenofovir gel would not have an impact on staff deployment or require task shifting. They thought tenofovir gel would be distributed first by nurses and then could eventually be broadened to CHWs and peer educators. Rather than framing it only as a burden for providers, many felt that counselling and testing would in fact be more fruitful and productive with a product to give women who test negative. Comments included: 
I don't see this as a burden for the nurses as they are already doing such tasks. Instead, they have more technologies to give their clients. This gel, for example, would generate a conversation around prevention after testing women negative.

It's not a real burden and can be easily incorporated into the scope of work for nurses. Nurses are technically doing risk-reduction counselling but have no products to give clients. This is an avenue for them to prioritise this some more. There is no need for task shifting as the nurses are already prescribing ARVs.

The nurses at a primary care level are already performing such tasks ... they are already 'task shifted.' We struggled to get nurses to prescribe ARVs and let's not make the same mistake with any other product.

A few KOLs said that although introduction of tenofovir might increase workload in the short term, if tenofovir reduces HIV incidence, in the long run it would reduce the burden on providers as they would not have to spend as much time treating and caring for HIV-positive clients.

Any trained health worker should want to offer all options-they should not feel like it's more work. Things change all the time. For example, ART was four times per day and now it's one pill with three drugs combined.

There was some comparison of tenofovir gel to VMMC, where there was push-back from both doctors and nurses. However, while tenofovir gel may involve some additional work, the level of training and changes in service delivery system would be much lower than with a surgical procedure. On the other hand, VMMC requires a one-time push to get a high proportion of males circumcised, while tenofovir gel would require sustainable supplies and ongoing testing and counselling.

The importance of pre-service training on HIV prevention (PMTCT, tenofovir gel, VMMC) was also emphasised; because HIV prevalence is so high in Zimbabwe, providers should have training in all existing and emerging HIV-prevention approaches during medical training.

A lot of money is being wasted by not getting things into pre-service [training]. Because people are not trained as part of their core curriculum, it means training on each new technology as it comes online.

It would be prudent to add HIV-prevention-training modules to pre-service curricula since HIV prevention is the future.

KOLs also described efforts to strengthen, coordinate, and streamline trainings, including moving training sessions from off-site at hotels to hands-on training in facilities.

People have been dying because so many health care workers are at trainings. Training should be short and sharp ... get in/get out with short, targeted training.

Although the discussion of training focused on nurses, respondents said that doctors, pharmacists, and CHWs in both public and private sectors should also be trained, so that tenofovir gel can be delivered by anyone in the health system.

\section{Supply chain and commodities security}

KOLs had a range of opinions about how to prepare for introduction with respect to the supply chain emphasising the need for the product to be available at the local level. Some felt that there would be no issue adding tenofovir gel into the existing supply chain whereas a few
Pre-service training will facilitate introduction of tenofovir (and other HIV-prevention methods). 
thought that the current supply chain must be improved before adding another commodity. A number of KOLs indicated that the current supply chain does not function, with frequent stock-outs of commodities. One respondent said:

Commodity assurance is critical, but we need to revamp the whole system of medical supply chains. Right now we are simply adding more weight to a dead horse in many respects. We have now realised the importance of private sector involvement in supply chains and manufacturing.

A KOL from the community explained:

The product needs to be available at an individual level and at a national level. There is no use talking about the product when we can't meet the supply.

Most KOLs thought it did not make sense to wait until the system is perfect to then introduce tenofovir gel (or other products).

This [commodities security] has been an issue in the treatment programme, but I don't think we can be perfect before we start. Remember we need to learn proper forecasting based on demand. Ultimately a good product will sell itself.

Commodities are a huge issue in HIV, but Zimbabwe has managed amidst hard times. We have shortages of essential medicines, and if we want to introduce the gel in such an environment we need to prioritise.

Many KOLs expressed concern about challenges with commodities security, with some referring to experiences with family planning commodities and the interplay of national and global systems. An $\mathrm{MOH}$ official said:

Supply issues and the regulatory framework restrict free market play for medicines in Zimbabwe. This means the government has to assure the public on commodity security, and it is important to liaise with the global community on this front.

\section{Pharmacovigilance/surveillance}

Respondents indicated that there were no existing pharmacovigilance or surveillance systems to build on to monitor tenofovir gel uptake, adverse reactions, and resistance.

This is an area that needs more work. We can't rely on the current system for phamacovigilance of such a new product that has not been used elsewhere.

Several respondents expressed frustration with the weakness of the current system, noting the significant investment that would be needed to strengthen it.

This [surveillance] needs to be strengthened and we are discussing how we can do that for treatment programmes. We currently don't know how much resistance, or have a collation of side effects from ARVs, and this just shows you the work that needs to be done.

Some KOLs thought that rolling out tenofovir gel could help strengthen such systems.

The gel may strengthen the system as a whole. At the moment we are supporting the post-marketing surveillance for oxytocin and we have seen the importance of surveillance and pharmacovigilance for improving maternal health. 
Surveillance...currently it is very weak, but maybe we should use this as an opportunity to strengthen all HIV surveillance including drug resistance.

\section{Cost, Economics, and Financing}

Cost was brought up spontaneously as a critical issue for determining whether or not to introduce tenofovir gel. Given that most health-related products are free or highly subsidised in Zimbabwe, high cost and price would significantly curtail access and affordability. For example, the majority of public health facilities provide family planning for free or for a small fee, such as US\$1.00 for a two- to five-month supply. One respondent felt it would be critical to ensure that tenofovir gel costs less than US\$1.00 per use.

Some respondents bundled cost issues with the existing challenges facing the health system that escalated in 2008 and have hindered health services overall. Cost considerations were largely seen as broader health systems issues rather than specifically related to tenofovir gel introduction, and some respondents felt that the introduction agenda should come with a health systems strengthening component.

The supply of the gel depends on the overall functioning of the health system; if it is functioning well, then the gel would be available long term.

Most respondents mentioned the need to engage the private sector in health service delivery to address these challenges.

Some of the health system challenges need to be financed by [the] private sector in a public/private partnership fashion, and I wouldn't rule this out in this project. If there are wiling partners who have money and can help us with health systems, we will be willing to partner.

I think everyone including [the] private sector could help, for example [through] segmentation and having the product available in the private sector so that we generate some revenue. Later on we could then introduce it into the public sector using donor support and then we need external funds.

\section{Short-term financing considerations for tenofovir gel introduction}

Most respondents felt that the Government of Zimbabwe would have overall responsibility for delivering tenofovir gel, however they recognised that in the current economic climate the gel would need to be funded primarily by outside donors, at least in the short term. PEPFAR was cited as a potential supporter by some respondents.

We expect to finance this through the partners, although government will have overall responsibility.

Government is primarily responsible to ensure people have access to such products. At the moment they can't afford [products] without donor support.

For many respondents, cost considerations also included the cost-effectiveness of the product, a view emphasised by a government official who said, "Cost effectiveness will guide us on how to incorporate this in our budgets."

Various actors are expected to be involved in tenofovir gel introduction in the short term, including the private sector. With unprecedented levels of poverty among the women who are
The private sector could provide an infusion of revenue to support introduction in the public sector. 
most vulnerable to HIV, it would not be realistic to expect them to pay for tenofovir gel. Therefore, some populations would need to access it for free or at a subsidised price.

\section{Long-term financing options for tenofovir gel}

While short-term financing was seen as a collective responsibility of the government and external donors, the government was viewed as being responsible for ensuring long-term sustainability. Some respondents talked about how introducing tenofovir gel would be part of the government's role in revamping the whole health system, including providing many other products. As such, long-term financing of tenofovir gel would not be an isolated policy decision, but would depend on the status of restructuring the health system.

Alternative financing options, such as the 3 percent AIDS levy (a deduction from tax returns of all employed people and corporations), were considered sources for long-term financing. Several respondents noted, however, that the AIDS levy was dependent on the performance of the economy overall. Some respondents felt that segmenting the market and benchmarking the price of tenofovir gel against condoms would generate revenue from the user and ensure long-term sustainability.

Although long-term financing options exalted the role of the government, respondents still felt that given the country's economic situation sustained supply would depend on external funding and private-sector involvement.

\section{Political Considerations}

Political risks could be mitigated by engaging a broad range of stakeholders early in the introduction process.
According to most respondents, a policy strategy for tenofovir gel would depend on the population that would be best and most effectively served by the product. Some HIV-prevention programmers cited tenofovir gel introduction as an opportunity to reach out to specific populations, such as sex workers. One senior-level government officer said:

We know the basis of disease control. We know where the commercial sex workers are, so this is an opportunity to target them.

However, others expressed concern about the feasibility and implications of targeting specific groups.

It is challenging to introduce for sex workers when sex work is illegal. How would it be seen if this is coming into the country and targeting CSWs? And then if you target youth, it could be seen as promoting promiscuity. So [introduction efforts] need to be very careful with positioning and messaging.

\section{Political risks of introducing tenofovir gel}

Respondents identified potential political risks that could emerge from different segments of society.

Advocacy groups: Most respondents felt that opposition from the advocacy community is unlikely, given the existing momentum that has positioned tenofovir gel as a tool to address gender inequities exacerbated by HIV. Since discussions about microbicides have emerged, women's groups have started advocating for women-controlled methods and would support introduction of an effective microbicide. The government, and particularly the $\mathrm{MOH}$, was 
seen as receptive to advocacy messages for prevention, especially from vocal HIV-positive advocates. Given enough information in advance, organisations embracing women's autonomy could help quell any concerns from other groups. Such organisations include women's groups, such as Women and AIDS Support Network (WASN) and the Musasa Project, and other information and advocacy organisations, such as the Southern Africa HIV and AIDS Information Dissemination Service (SAfAIDS). Organisations with an equity and human rights perspective were also seen as essential for obtaining support for tenofovir gel introduction.

Although low levels of efficacy were seen as possibly dampening advocacy support, one respondent said, "Risks will depend on how it [tenofovir gel] is marketed."

As long as tenofovir gel is cost-effective, respondents felt government support would help advocacy groups to make the case. Most HIV-prevention advocacy has come from treatment-support groups, which has led to both tension and synergies in the advocacy community between prevention and treatment groups. For example:

Pressure comes from infected people who need treatment. Balance is needed between prevention and treatment cost.

Advocacy groups, particularly groups who need treatment, would support prevention efforts. If you shorten [the] queue, you may actually get your treatment faster.

Some respondents also saw the need for researchers working on microbicide trials to be involved in garnering support from advocacy groups. According to one civil society representative:

I have seen researchers championing this so I would think they would help in communicating this based on their clinical trial experience.

Community groups: Some respondents mentioned that activities designed to ensure that communities are receptive to research could be used as a starting point for disseminating information when a product is ready to be introduced. If communities have accepted research, introducing a microbicide should flow smoothly. In addition, some respondents felt that because Zimbabwe has been successful in HIV-prevention efforts, reflected in its declining prevalence, new products would be welcome. One respondent said:

In a society that has accepted condoms, I do not foresee an outcry in the introduction of the gel.

Community acceptability would be enhanced through a clear communication strategy. Cultivating champions at an early stage was also seen as essential to community buy-in. Finally, one respondent suggested that the gel should be approached from a health standpoint, because a women's-rights-based approach could risk backlash. Different approaches may need to be taken with different constituencies, and the implications would need careful consideration.

Men's perspectives: General acceptability among men was viewed as important to mitigate political risks. For example, a leader in a men's organisation stated:

Acceptability to men is key, as presenting a product as a prevention tool for women implies that men are bringing the HIV into the relationship and potentially would cause an outcry from men's organisations. 
Addressing men's perceptions and preferences was also mentioned by another respondent who said that tenofovir gel could be a problem for men who prefer dry sex.

Religious and cultural groups: Overall, respondents did not foresee that religious organisations would pose a major barrier to tenofovir gel introduction. One respondent stated that there have been instances where church leaders have opposed HIV testing and counselling campaigns, alleging that the government was promoting promiscuity among adolescents. The Apostolic Faith Church was cited several times as a potential barrier because it usually opposes anything to do with safe-sex campaigns and HIV.

Some respondents talked about the potential for opposition by cultural groups with a tradition of dry sex. Education about dry sex would need to be incorporated into tenofovir-gel communication strategies.

\section{Engaging stakeholders}

Early stakeholder involvement was emphasised, although the exact timing and nature of such participation was difficult to specify. Some respondents suggested establishing a working group comprised of the $\mathrm{MOH}$ and other key stakeholders, embracing a broad approach. Most KOLs felt that some involvement is needed before the trial results are available, although doing so needs to be balanced with managing expectations. Once trial results are available, communication should target a much wider population if tenofovir gel is shown to be effective.

In addition to the $\mathrm{MOH}$, the key stakeholder for successful introduction, the Ministries of Education and Finance were also seen as important. As noted earlier, regulatory frameworks and authorities will play a central role. Some respondents emphasised that the $\mathrm{MOH}$ should be involved in designing implementation and operations research so that findings can quickly move into policy. Some expressed frustration at the length of time it takes to move from scientific evidence to policy, as has been the case with treatment as prevention (TASP). Although Zimbabwe was a site for the HPTN 052 study that showed 96 percent reduction in HIV acquisition among sero-negative partners of HIV-positive individuals on treatment (Cohen et al. 2011), TASP has still not yet been widely implemented in Zimbabwe. Some KOLs were pessimistic about the length of time it would take to make tenofovir gel accessible, unless it were 100 percent effective.

Other groups mentioned as important in defining and implementing an introduction agenda for tenofovir gel included NGOs involved in social marketing, such as PSI, and advocacy and communications groups like WASN, SAfAIDS, Musasa Project, and networks of people living with HIV. Multilateral agencies such as UNAIDS, UNFPA, and WHO were also seen as important, and a few respondents also recommended including key professional associations, such as obstetricians, gynaecologists, and nursing organisations.

It is important to keep news coming, put stories in the newspaper, have a presence at conferences, satellite meetings. Ask KOLs how they get their information to make sure the information keeps flowing to them.

\section{Champions and potential champions for tenofovir gel introduction}

Most respondents stated that while there are some groups that advocate for HIV prevention, these advocacy efforts are scattered and not well organised. Most respondents were not 
aware of any groups that are advocating specifically for ARV-based prevention in Zimbabwe; those who seemed most knowledgeable were somehow linked to ARV-based prevention research. Groups of people living with HIV were noted as having close links to the ARV-based prevention agenda, and sometimes these groups advocate for prevention. Several respondents cited the $\mathrm{MOH}$ as a potential champion for prevention.

No one person was mentioned as currently being a champion for microbicides, because they are not yet available or well known. However, several individuals and organisations were mentioned who could potentially play such a role, including people working within the $\mathrm{MOH}$ and those working on women's issues in civil society. For example, groups like WASN could potentially play this role if provided with appropriate information and exposure.

Respondents noted that current champions for microbicides are mainly linked to microbicide research and that it would be important going forward to build broader advocacy for woman-controlled prevention.

There is need for advocates for women's products. Prevention advocacy organisations could do that, but so far researchers are doing it well.

Some respondents said that it could be premature to advocate for a specific product like tenofovir gel before the clinical trial results are available.

\section{Perspectives on opportunities missed by not introducing tenofovir gel}

A number of the respondents believed that tenofovir gel should be introduced only if it is highly effective, although there were differing perceptions of what "highly" effective meant. Others, however, felt that there is a need to balance efficacy with the need to offer women options that they can use. The opportunity costs of not introducing the product would then depend partly on this balance as reflected in these different perspectives.

At 40 percent, though, the opportunity costs of not introducing are very low.

There is potential loss of letting a product that is cost-effective and highly efficacious go, but we can get to real figures when we get the data.

There are costs for not introducing tenofovir gel since women would still have no options for HIV prevention. These are opportunity costs for lives saved, and this depends on efficacy. It would be a pity not to see the tenofovir gel on the shelves because I believe it has the potential to reduce HIV incidence. The loss will be more for women in Zimbabwe.

\section{Lessons from Other Technology Introduction}

Lessons cited were primarily from female condom distribution programmes and the introduction of medical male circumcision. The major lessons centered around health systems issues, supply chain, and information dissemination. One respondent suggested that any lessons to be learned should be from the private sector, but there was little specific analysis or examples of how this applied to subsidised products or products that need to be supplied with health services. 
Female condom: Comments regarding lessons from the female condom, another femaleinitiated HIV-prevention tool, focused on the importance of providing the right information, especially to providers.

We never thought female condom uptake would improve, but people who are informed are coming to use it. It needed health providers to be able to demonstrate it properly and provide information on the female condom with proper instructions.

In addition, respondents noted the need to work with organisations and to engage communities to advocate for female-initiated prevention methods, as was the case with female condoms:

Women's advocates in Zimbabwe have been successful in promoting female condoms. There are [also] male advocacy groups... who have promoted these products in the past.

Voluntary medical male circumcision: The importance of partner involvement was one lesson to be drawn from VMMC, as noted by two respondents who attributed lower than anticipated demand to the limited inclusion of women in VMMC campaigns. Avenues for male involvement could include partner counselling, as is now occurring with MC, and effective packaging of information, such as marketing microbicides to improve sexual pleasure. Conveying partial effectiveness is a challenge, and lessons, both positive and negative, could be drawn from experiences with scale-up of MC services. Other specific insights cited by some of the respondents include:

Demand for MMC is lower than what had been hoped for or expected. It will be important to be realistic in assessing demand for tenofovir gel, while also beginning to generate demand for a new product, and to engage people early (even now, before results are available).

- It is important to consider the cadre of health care workers who would introduce tenofovir gel. MC was initially being conducted by physicians, and acceptability of having a lower cadre of health workers provide the service has proven challenging in some settings.

PMTCT programmes: Most lessons cited from PMTCT programmes centered on the importance of proper planning and the downside of changing regimens frequently. An example cited was the introduction of a single dose of Nevirapine, and the importance of providing accurate information even in a dynamic and evolving situation:

If you give new information, make sure it's accurate. People were told they could take a single dose [of Nevirapine], but were not told the whole story of how three doses is optimal ... and then there was backlash.

HIV treatment programmes: One respondent, in referring to transitioning HIV care and treatment from physicians to nurses and, ultimately, to CHWs, said, "Task shifting, which should be a 'no brainer,' took most countries years to figure out how to do it well, and in doing so cost them money." Challenges with adherence were also mentioned, with one respondent posing the question, "If sick clients can't adhere to their regimens, how much more [challenging will it be for] those who are not sick having to use the gel every day?"

Pilot projects: As is the case with other technology-introduction efforts, pilot projects should not be too long as to lose momentum and jeopardise public perception. Some respondents felt that an introduction agenda should immediately move to full-scale implementation. 
Another view was the need for building a healthy marketplace before introduction to ensure there is more than one provider, public and private suppliers, and a mixture of cadres of health care workers delivering services, as this will drive down costs and ensure supply. 


\section{THE WAY FORWARD: PREPARING FOR INTRODUCTION}

Overall, there was broad support for introduction of tenofovir gel as an HIV-prevention technology for Zimbabwe, pending positive results of the FACTS 001 trial. Respondents had a variety of opinions about activities that should and could be undertaken to prepare for tenofovir gel introduction while waiting for the trial results, versus what would need to wait until after the trial results are known. The following section summarises recommendations for keeping the tenofovir gel introduction agenda moving forward, while avoiding raising expectations. Activities include those that can be done now while waiting for the FACTS trial results, and those that would be implemented if the trial confirms tenofovir's effectiveness.

Activities that can be initiated while awaiting results of the FACTS 001 trial include:

- Expanding stakeholder engagement: Most KOLs emphasised the need for wider stakeholder engagement, especially with the $\mathrm{MOH}$ and the MCAZ, to accelerate regulatory and programmatic processes should tenofovir gel be proven efficacious. KOLS felt the government should lead future stakeholder engagement, potentially through the creation of a technical working group on tenofovir gel, a strategy that has been used with other technology-introduction efforts. PPFs were cited as a mechanism for ensuring broad stakeholder involvement.

- Cultivating champions for tenofovir gel: Specific individuals were mentioned as potential champions who could be cultivated as champions for ARV-based prevention for women, including tenofovir gel and other products in the pipeline.

- Obtaining input from health care providers: Recognizing the important gate-keeping role that service providers and programme managers play, their approval and "adoption" is critical for the success of any product. Obtaining providers' input into the design of services was seen as key to the successful delivery of programmes. Respondents recommended conducting FGDs and in-depth interviews with a range of service providers and programme managers to involve them in the discussion and planning for introduction now, as well as conducting workshops to explore options for service delivery and programme design.

- Convening information-sharing sessions: Ongoing information-sharing sessions were encouraged as a way to ensure that information about tenofovir gel continues to reach stakeholders in Zimbabwe. KOLs underscored the importance of identifying effective communication channels among product developers, clinical trial researchers, and other interested parties so that updated information and status of trials will be shared.

- Increasing advocacy for female-initiated prevention methods: Increasing advocacy and information about female-initiated prevention in general was seen as paving the path for rolling out a product, once available. There was some concern, however, that widespread discussion may be premature and that the conversation should be limited to a few individuals now and only be expanded after the release of the FACTS trial results, which will determine messaging, market segmentation, and channels of distribution.

- Conducting acceptability and feasibility studies: FGDs among women and male partners-even while waiting for the confirmatory results from the FACTS 001 trial- 
were recommended for exploring how well people understand partial effectiveness, whether they would be interested in tenofovir gel, and how best to market the gel so that it would also be acceptable to men. KOLs emphasised the need to gather men's opinions early in the process, to explore how people would feel about the gel in areas where dry sex is practiced, and to gather perspectives from both urban and rural settings.

Developing operational plans: Some respondents felt there is a need to begin developing operational plans, monitoring and evaluation plans, and costing plans while waiting for the FACTS trial results. Other activities that would be beneficial would be optimizing procurement and manufacturing systems and supply chains.

- Continuing research to find more efficacious products: Respondents highlighted the need for research to continue to find products that are likely to be more efficacious than 1 percent tenofovir gel. Exploring different compounds-or combinations of drugs, as have been used in HIV treatment-and alternative formulations (such as intravaginal rings) were mentioned.

Activities that would only be undertaken if the FACTS 001 trial results confirm tenofovir's effectiveness prior to (or in parallel with) regulatory approval and licensure, include:

- Implementing demonstration projects: Implementing demonstration projects in Zimbabwe was viewed as a critical activity once data confirmed tenofovir gel's effectiveness. However, some respondents indicated such studies could be Phase 4 post-marketing studies, whereas others felt local demonstration projects would need to be implemented prior to making the decision to approve and distribute tenofovir gel in Zimbabwe. Demonstration projects would enable further assessment of acceptability within the Zimbabwean context, including both urban and rural areas.

- Developing provider training plans and materials; training providers (in-service and pre-service): Many respondents talked about the importance of incorporating training into pre-service curricula to improve scale-up and sustainability of any new technology introduced. 


\section{REFERENCES}

Abdool-Karim, Q. et al. 2010. "Effectiveness and safety of tenofovir gel, an antiretroviral microbicide, for the prevention of HIV infection in women." Science 329(5996): 1168-1174. doi:10.1126/ science.1193748.

Cohen, M.S. et al. 2011. "Prevention of HIV-1 infection with early antiretroviral therapy." New England Journal of Medicine 365(6):493-505. doi: 10.1056/NEJMoa1105243.

FACTS Consortium. 2013. Available at: <http://www.facts-consortium.co.za/?page_id=83>. Accessed 12 August 2013.

Hargrove, J.W. et al. 2011. "Declining HIV prevalence and incidence in perinatal women in Harare, Zimbabwe.” Epidemics 3(2):88-94. doi: 10.1016/j.epidem.2011.02.004.

IRIN NEWS. 2011. ZIMBABWE: New treatment guidelines rolled out-a year later. Available at: <http://www.irinnews.org/report/92452/zimbabwe-new-treatment-guidelines-rolled-out-ayear-later>. Accessed 13 August 2013.

Microbicide Trials Network (MTN). 2013. Understanding the results of VOICE. Available at: <http://www.mtnstopshiv.org/node/2003>. Accessed 12 August 2013.

Obiero, J. et al. 2012. "Vaginal microbicides for reducing the risk of sexual acquisition of HIV infection in women: Systematic review and meta-analysis." BMC Infectious Diseases 12:289. doi: 10.1186/1471-2334-12-289.

UNAIDS. AIDSinfo 2013. Available at: <http://www.unaids.org/en/regionscountries/countries/ zimbabwe/>. Accessed 20 August 2013.

US Food and Drug Administration (FDA). 2013. Drugs @FDA. Available at: <http://www. accessdata.fda.gov/scripts/cder/drugsatfda/index.cfm?fuseaction=Search.Label_ApprovalHistory\#apphist>. Accessed 12 August 2013.

van de Wijgert, J. et al. 2001. "Phase 1 trial of the topical microbicide BufferGel: Safety results from four international sites." Journal of Acquired Immune Deficiency Syndromes 26(1):21-27.

Zimbabwe National Statistics Agency (ZIMSTAT) and ICF International. 2012. Zimbabwe Demographic and Health Survey 2010-11. Calverton, MD: ZIMSTAT and ICF International. 


\section{APPENDIX 1: DISCUSSION GUIDE FOR KEY OPINION LEADERS AND DECISIONMAKERS}

\section{MODULE 2}

\section{DISCUSSION GUIDE FOR KEY OPINION LEADERS AND DECISIONMAKERS}

This tool is designed to engage key decisionmakers who will be involved in or influence strategic decisions about introducing and rolling tenofovir gel for women in a country. Through exploring views and eliciting expert opinion, it identifies key questions and issues that must be considered and addressed to inform decisions about introducing new products in the context of a country's particular HIV epidemic, health system, and political and economic environment. Companion guides have been developed that complement the information gathered here through: (1) compiling key demographic and health information in a "Landscape Analysis" and (2) examining in more depth the health system capacity and adaptations needed to deliver a new HIV prevention product.

This tool is intended to guide individual in-depth interviews with carefully selected key opinion leaders and decisionmakers, conducted by a senior peer leader working in the HIV field. As such, it assumes a fairly high level of knowledge and awareness of critical issues in HIV prevention and of the policy-making environment in the country. It considers scientific, political and economic factors that drive decisionmaking, as well as general issues related to health system capacity.

NOTE: This version of the tool is oriented to tenofovir gel, but it can be adapted for other specific products such as the dapivirine ring or Truvada for pre-exposure prophylaxis (PrEP).

\section{SCIENTIFIC EVIDENCE ON TENOFOVIR GEL}

Evidence to date suggests tenofovir gel is safe and two effectiveness trials have been conducted: one showed a 39 percent reduction in risk (and 54 percent reduction among those who reported most consistent use), and the other was stopped early because no effect was observed. A third effectiveness trial is underway and is expected to be completed in 2014. In addition, other HIV prevention products are at various phases of development and introduction. At this stage, we would like your insights on key areas and critical issues related to introduction of tenofovir gel.

1. How could information related to the following issues be used by the national health system to support introducing tenofovir gel in your country?

- Safety: during pregnancy, during breastfeeding, during adolescence, potential resistance, impact on fertility, specific populations

- Effectiveness (how well it works)

- User acceptability (adherence, behaviors)

- Regulatory status and licensure

- Any other technical review processes (e.g., WHO guidelines)

- Manufacturing and supply chain

- Cost

- Other issues 


\section{RATIONALE FOR TENOVOFIR GEL: PUBLIC HEALTH IMPACT, INDIVIDUAL RIGHTS AND EQUITY}

The introduction of a new HIV prevention product holds the potential for public health impact, reducing individuals' risk, and contributing to equity. The field of HIV prevention includes a broad range of stakeholders and potential users.

2. In your view, who do you think will benefit most from using tenofovir gel and why? In what situations?

\section{Probe, as needed:}

- Sero-discordant couples?

- Young women?

- Married women? (Married women whose husbands work away)?

- Sex workers?

- Women who have infrequent, but risky sex (e.g. exchange sex for money, food, shelter)?

- Women with multiple partners?

- Women whose partner has multiple partners?

3. Where do you see tenofovir gel fitting into your country's HIV prevention program vis-à-vis existing strategies (e.g., HIV counseling and testing ,condom promotion, male circumcision, behavior change communications, oral PrEP, others)?

4. Within your health system, what do you see as the best opportunities for delivering tenofovir gel? By which sectors (public, non-government organization, private sector)?

- Within HIV programs? (Treatment programs? Counseling and testing? Other prevention programs?)

- Within reproductive health programs?

5. How would you prioritize tenofovir gel relative to other HIV prevention strategies and why?

\section{IMPACT ON HEALTH SYSTEMS}

The addition of a new HIV prevention product provides opportunities to improve services, while also adding challenges on already overburdened health systems. What are your views about how tenofovir gel introduction would affect various aspects of the system?

6. If tenofovir gel was introduced in your country, what do you think would be the implications for the following:

- HIV testing programs

- HIV treatment programs

- Resource allocation

- Staff deployment, task shifting

- Commodities security

- Pharmaco-vigilance/surveillance 


\section{POLICY CONSIDERATIONS}

7. What do you see as potential political gains and political risks from introducing tenofovir gel?

\section{Probe as needed:}

- Expanded options for prevention

- Equity

- Reactions from various constituencies-religious, community, advocacy groups

8. Who are the key players (organizations) that must be engaged in the decision about whether to introduce tenofovir gel?

9. Are there champions for antiretroviral-based prevention in your country? for HIV preventon for women? tenofovir gel specifically? Who could potentially play this role?

10. Do you see any potential costs of NOT introducing tenofovir gel?

\section{ECONOMICS, COST, AND FINANCING}

Cost considerations often factor heavily in decisions about whether, how, and at what scale new health products might be introduced. This is the case with HIV treatment and prevention products, but is particularly relevant in the area of prevention. Planning for how an HIV prevention product and its delivery will be financed is critical to sustainability. It is important to note that cost of products during clinical trials and initial introduction stages generally higher than what might be expected when product is manufactured at scale.

11. How do you see tenofovir gel being financed in the short term? Who will pay for it?

12. How do you think tenofovir gel supply to those who need it could be sustained over the long term?

13. How would the decision be made whether to invest in tenofovir gel introduction?

14. What would you need to know to make the investment case for tenofovir gel at this point? To allocate a budget for product procurement and introduction?

\section{SUMMARY}

15. How would you prioritize the introduction of tenofovir gel for HIV prevention?

16. Are there lessons (positive and negative) from the introduction of other technologies or prevention strategies that could inform tenofovir gel introduction plans?

17. From your position and the role that you/your agency plays, what other information/data would you need to make a decision about introducing tenofovir gel?

18. If you were asked to make a decision today about whether to introduce tenofovir gel, what would that be? Why?

Excerpted from: Population Council. (Unpublished). "A toolkit for strategic decisionmaking and planning for microbicides," Draft. New York: Population Council. 


\section{APPENDIX 2: ORGANISATIONS REPRESENTED}

We are grateful to the individuals from the following organisations who were willing to share their time, opinions, and expertise with us for this research.

- Centers for Disease Control and Prevention (CDC)-Zimbabwe, US Department of Health and Human Services

- Centre for Sexual Health and HIV/AIDS Research (CeSHHAR)

- Clinton Health Access Initiative (CHAl) Zimbabwe

- Maternal and Child Health Integrated Program (MCHIP)

- Medicines Control Authority of Zimbabwe

- Ministry of Health, AIDS and TB Programme, and PMTCT and Pediatric HIV Care and Treatment

- Ministry of Health and Child Welfare, AIDS and TB Unit

$\checkmark$ National AIDS Council

- National Medicine and Therapeutics Policy Advisory Committee (NMTPAC)

- Organisation for Public Health Interventions and Development (OPHID)

- Padare/Enkundleni/Men's Forum on Gender

$\checkmark$ UNFPA

- University of Zimbabwe, College of Health Sciences, Department of Obstetrics \& Gynecology

$\checkmark$ USAID

Zimbabwe AIDS Prevention Project (ZAPP)

- Zimbabwe National Family Planning Council (ZNFPC) 

Population Council

One Dag Hammarskjold Plaza

9th Floor

New York, New York 10017

www.popcouncil.org 